\title{
Impairment of germline transmission after blastocyst injection with murine embryonic stem cells cultured with mouse hepatitis virus and mouse minute virus
}

\author{
E. Mahabir $\cdot$ K. Reindl · J. Mysliwietz $\cdot$ \\ J. Needham · D. Bulian · K. Markoullis · \\ H. Scherb · J. Schmidt
}

Received: 20 August 2008/Accepted: 25 August 2008/Published online: 18 September 2008

(C) Springer Science+Business Media B.V. 2008

\begin{abstract}
The aim of this study was to determine the susceptibility of murine embryonic stem (mESCs) to mouse hepatitis virus (MHV-A59) and mouse minute virus (MMVp) and the effect of these viruses on germline transmission (GLT) and the serological status of recipients and pups. When recipients received 10 blastocysts, each injected with $10^{\circ}$ TCID $_{50}$ MHVA59, three out of five recipients and four out of 14 pups
\end{abstract}

E. Mahabir $(\bowtie) \cdot$ K. Reindl · D. Bulian .

K. Markoullis · J. Schmidt

Department of Comparative Medicine, Helmholtz Center

Munich, German Research Center for Environmental

Health, 85764 Neuherberg, Germany

e-mail: mahabir@helmholtz-muenchen.de

Present Address:

K. Reindl

Max Planck Institute for Biochemistry,

Am Klopferspitz 18, 82152 Martinsried, Germany

J. Mysliwietz

Institute of Molecular Immunology, Helmholtz Center Munich, German Research Center for Environmental Health, Ingolstädter Landstraße 1, 85764 Neuherberg, Germany

J. Needham

The Microbiology Laboratories, North Harrow, Middlesex, UK

H. Scherb

Institute of Biomathematics and Biometry, Helmholtz Center Munich, Ingolstädter Landstraße 1, 85764

Neuherberg, Germany from three litters became seropositive. When blastocysts were injected with $10^{-5}$ TCID $_{50}$ MMVp, all four recipients and 14 pups from four litters remained seronegative. The mESCs replicated MHV-A59 but not MMVp, MHV-A59 being cytolytic for mESCs. Exposure of mESCs to the viruses over four to five passages but not for $6 \mathrm{~h}$ affected GLT. Recipients were seropositive for MHV-A59 but not for MMVp when mESCs were cultured with the virus over four or five passages. The data show that GLT is affected by viruscontaminated mESCs.

Keywords Murine embryonic stem cells · Germline transmission - Mouse hepatitis virus . Mouse minute virus

\section{Introduction}

Transfection of murine embryonic stem cells (mESCs) with the desired gene constructs and injection into blastocysts coupled with transfer to suitable recipients is a standardized method for producing transgenic mice (Gossler et al. 1986). However, besides feeder cells and blastocysts, mESCs can harbor murine pathogens (Okumura et al. 1996; Kyuwa et al. 1997) and their introduction into a mouse colony can lead to spread of infections. Due to the exchange of mESCs between laboratories worldwide the risk of transmitting mouse infectious agents may even be higher since mESCs are often not 
screened for viruses and contamination and infection with viruses cannot be detected on the basis of cell morphology.

Mouse hepatitis virus (MHV) and mouse minute virus (MMV) have a size of 80-160 nm and $20 \mathrm{~nm}$, respectively, and are infectious agents that are relevant for routine health monitoring of contemporary mouse colonies (Nicklas et al. 2002). MHV belongs to the coronavirus family of enveloped, positive-strand ribonucleic acid (RNA) viruses and its replication occurs in the cytoplasm of cells (Brayton et al. 1981; Gosert et al. 2002). MMV is a non-enveloped, linear positive-strand deoxyribonucleic acid (DNA) virus of the Parvoviridae family and replicates in the nucleus of mitotically active cells (Tattersall 1972; Linser et al. 1979).

Although a survey of $46 \mathrm{mESC}$ lines did not show the presence of murine infectious agents (Nicklas and Weiss 2000) two studies showed that murine mESCs became infected with MHV-2 and MHV-A59 and continued to grow in vitro showing neither cytopathic effects nor overt signs of differentiation (Okumura et al. 1996; Kyuwa 1997). Since these studies were performed in vitro no information is available on whether transferring blastocysts which have been injected with virus-exposed mESCs to recipients affects the germline efficiency of the mESCs and if and how soon after embryo transfer the recipients and pups show specific antibodies to such viruses. This is of relevance to laboratory animal science since germline transmission (GLT) is a necessity for the production and use of transgenic mice. Also, infected mice affect the outcome of animal experiments (Fox et al. 1977; Kyriazis et al. 1979; Dempsey et al. 1986; Barthold 1986; Lussier 1988).

In the present study, the objectives were to (1) investigate the susceptibility of mESCs to infection with MHV-A59 and MMVp, (2) investigate the effect of MHV-A59- and MMVp-exposed mESCs on GLT and the reproductive performance of the recipients, and (3) determine the serological status of recipients and pups under routine working conditions at our mouse facility.

\section{Materials and methods}

Cells and viruses

Virus stocks of MHV-A59 (VR-764) and MMVp (VR-1346) and their producer cell lines NCTC-1469
(CCL-9.1) and A9 (CCL-1.4), respectively, and L929 cells (CCL-1) were obtained from the American Type Culture Collection (Manassas, VA, USA). NCTC1469 and A9 were used for propagation of MHV-A59 and MMVp, respectively, while L929 cells were used for titration of both viruses. NCTC-1469, A9, and L929 cell cultures were maintained in Dulbecco's modified Eagle's medium (DMEM) supplemented

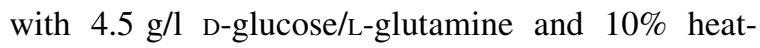
inactivated fetal calf serum (L929 in 5\% fetal calf serum). Propagation of virus stocks was performed in $75 \mathrm{~cm}^{2}$ cell culture flasks (NCTC-1469 in cell culture flasks from Corning Costar, Cambridge, Maryland, USA; A9 and L929 in cell culture flasks obtained from Nunc, Roskilde, DK) at $37^{\circ} \mathrm{C}$ using $5 \% \mathrm{CO}_{2}$ in a humidified atmosphere. Cultures of permissive cells were infected with the appropriate virus for $1 \mathrm{~h}$ followed by removal of the virus suspension and replacing it with $10 \mathrm{ml}$ cell culture medium. MHVA59- and MMVp-infected cells were frozen in their culture flasks after $20 \mathrm{~h}$ and 5 days, respectively. They were subjected to three freeze-thaw cycles to allow release of the virus. The contents of the flasks were centrifuged at $3,000 \mathrm{~g}$ for $5 \mathrm{~min}$ to separate virus from cell debris. The supernatant was passed through a Minisart ${ }^{\circledR}$ filter having a pore size of $0.20 \mu \mathrm{m}$ (Sartorius, Göttingen, Germany). For titration, L929 cells were seeded in 96-well plates at a concentration of $2 \times 10^{4} /$ well for MHV-A59 and $3 \times 10^{3} /$ well for MMVp and cultured overnight. After removal of the culture medium, for each 10 -fold dilution up to $10^{-10}, 12$ wells were inoculated with $100 \mu \mathrm{l}$ of the virus. The cytopathic effect (CPE), observed as syncytia and cytolysis for MHV-A59 and detachment of cells for the MMVp infection, was determined on the second and sixth day of culture, respectively. The mean tissue culture infective dose $\left(\mathrm{TCID}_{50}\right)$ for each viral stock was calculated according to the Spearman-Kaerber method (Spearman 1908; Kaerber 1931). The MHV-A59 and MMVp stocks used in this study had titers of $10^{9}$ and $10^{4} \mathrm{TCID}_{50} / \mathrm{ml}$, respectively, and were stored at $-80^{\circ} \mathrm{C}$ until used.

Mice and husbandry

Outbred Crl:CD1(Icr)/Dcm (Dcm = Department of Comparative Medicine) mice were bred in a full barrier unit at our animal facilities. Breeding colonies were kept in filter-topped Type II Makrolon ${ }^{\circledR}$ cages at 
a temperature of $20-24^{\circ} \mathrm{C}$, humidity of $50-60 \%, 20$ air exchanges per hour and a 12/12-h light/dark cycle. Wood shavings (Altromin, Lage, Germany) were provided as bedding. Mice were fed a standardized mouse diet (1314, Altromin) and provided drinking water ad libitum.

Staff wore clean suits, disposable gloves, bonnets, and face masks. Mice were transferred to new individually ventilated cages (IVCs, VentiRacks ${ }^{\mathrm{TM}}$; BioZone, Margate, UK) in class II laminar flow changing stations with disinfected forceps padded with silicone tubing. All materials were autoclaved before use.

Microbiological examination of mouse colonies was performed every 6 weeks using male $\mathrm{Crl}$ :CD1(Icr)/Dcm sentinels from the colony as described (Mahabir et al. 2007). Briefly, aliquots of approximately $5 \mathrm{~cm}^{3}$ of soiled bedding were taken from each used cage on a rack. These aliquots were mixed in a sterile box with an equivalent amount of new sterile bedding, and the resultant mixture was distributed to the sentinel cage of the same rack over a period of 12 weeks. The serological examinations were performed according to the annual standard recommended by FELASA (Federation of Laboratory Animal Science Associations) (Nicklas et al. 2002) with the addition of Leptospira serogroups, ballum, canicola, hebdomadis, and icterohaemorrhagiae, $\mathrm{K}$ virus, Lactate dehydrogenase virus, Polyoma virus, Mouse thymic virus, Hantaviruses (Kraft et al. 1994), and since October 2006 murine norovirus. The mice were found consistently negative for all of the abovementioned infectious agents including the ones examined in this study.

Experimental and control mice were kept in IVCs under positive pressure and the conditions stated above. All animal manipulations were performed in a class II laminar flow biological safety cabinet (Heraeus Instruments GmbH, Munich, Germany). All animal studies were approved by the Helmholtz Center Munich institutional animal care and use committee and the Government of Upper Bavaria, Germany (211-2531-8/02).

Experiment 1: blastocyst injection with MHV-A59 and MMVp

About 6 to 8-week-old Crl:CD1(Icr)/Dcm females were induced to ovulate by intraperitoneal injections of 5 IU equine Chorionic Gonadotropin (eCG; Intervet, Boxmeer, The Netherlands) followed $48 \mathrm{~h}$ later by $5 \mathrm{IU}$ human Chorionic Gonadotropin (hCG; Intervet). They were mated immediately thereafter with males of proven fertility. The presence of vaginal plugs was determined the following morning (d0.5). Mice were killed on d3.5, blastocysts were flushed from the uterine horns and collected in M2 medium (Quinn et al. 1982).

To determine if injection of MHV-A59 and MMVp into blastocysts led to the birth of pups and if mice seroconverted, approximately $1 \mathrm{nl}$ of each viral stock was injected into each blastocyst using a micromanipulator (Leitz, Bensheim, Germany). A total of 50 and 40 embryos was injected with MHVA59 and MMVp, respectively. For the control group, 20 embryos were injected with ESC medium. First, control then viral-exposed blastocysts were injected.

\section{Embryo transfer}

A total of five blastocysts was transferred to each uterus horn of $\mathrm{d} 2.5$ pseudopregnant recipients as described (Nagy et al. 2003). First, control then viralexposed blastocysts were transferred. Recipients were kept singly in IVCs. Pups were kept with their mothers until weaning at 21 days postpartum and then singly in IVCs.

\section{Serological analysis}

To determine if the recipients seroconverted and the time of seroconversion, sera were prepared on days 14, 21, 28, 42, and 63 after embryo transfer. Sera from progeny were prepared on days $42,63,84$, and 112 after embryo transfer to determine if the progeny were seropositive and if this antibody was maternal in origin or if the progeny themselves became infected with the virus. Blood was taken from mice receiving control blastocysts then from mice receiving viralexposed blastocysts.

Sera were diluted 1 in 10 in phosphate-buffered saline (PBS; Oxoid, Hants, UK) containing 0.05\% Tween 20 (R \& L Slaughter, Essex, UK). They were tested for specific antibodies (IgG whole molecule) to MHV and MMV by use of an enzyme-linked immunosorbent assay (ELISA) using control nonviral-coated and viral-coated plates and negative and positive serum. The MHV and MMV antigens were 
obtained from Churchill Applied Biotechnology Ltd. (Cambridgeshire, UK). The optical density (OD) was read at $492 \mathrm{~nm}$ with a Multiskan ELISA plate reader (Thermo Life Sciences, Hampshire, UK). Sera were equivocal low positive when the OD was 0.6000.799 and positive when OD values exceeded 0.799 .

\section{PCR analysis of organ samples from pups}

For PCR analysis, three pups from each of the three groups investigated in Experiment 1 were killed within 3 days of birth and organs were collected. With regard to the MHV PCR, total RNA from the liver and the intestine was extracted using the QIAamp viral RNA mini kit (Qiagen, Hilden, Germany) according to the manufacturer's instructions. Precipitated RNA was taken up in $60 \mu \mathrm{l}$ RNase-free AVE buffer which is also provided in the kit. The DNA present was removed by RNase-free DNase (Qiagen). Immediately thereafter, an RNase inhibitor (MBI Fermentas, St. Leon-Rot, Germany) was added to the RT mixture at a concentration of $10 \mathrm{U} / \mu \mathrm{l}$. cDNA was synthesized using $12 \mu \mathrm{l}$ RNA and the Omniscript Reverse Transcriptase kit (Qiagen). For PCR analysis, $1 \mu \mathrm{g}(\mu \mathrm{l}) \mathrm{cDNA}$ was used for amplification. The primers used were those designed by Taylor and Copley (1994): 5'-CAGCCTGCCTCTACTGTAAAACC-3' (forward), 5'GCCTCCAAAATTCTGATTGGGGC-3' (reverse), yielding a 225-bp product. A double-distilled water sample was used as a negative control in both the RT and the PCR steps. PCR was performed in a total volume of $20 \mu \mathrm{l}$ using Taq DNA polymerase (Qiagen) for 35 cycles in a thermocycler (Biometra, Biomedizinische Analytik GmbH, Göttingen, Germany). Denaturation was performed at $94^{\circ} \mathrm{C}$ for $4 \mathrm{~min}$. Each cycle consisted of $94^{\circ} \mathrm{C}(60 \mathrm{~s}), 57^{\circ} \mathrm{C}(60 \mathrm{~s})$, and $72^{\circ} \mathrm{C}$ $(45 \mathrm{~s})$. The last cycle was followed by a 10 -min extension period at $72^{\circ} \mathrm{C}$.

DNA from the spleen and the kidney for the MMV PCR was extracted using the QIAamp DNA mini kit (Qiagen) according to the manufacturer's instructions. The primers used were those designed by Bootz et al. (2003) as follows: 5'-GAGCGCCATCTAGTGAG C-3' (forward) and 5'-ATTTGCCTGTGCTGGCT G-3' (reverse), yielding a 483-bp product. A doubledistilled water sample served as a negative PCR control. PCR was performed in a total volume of $20 \mu \mathrm{l}$ using Taq DNA polymerase (Qiagen) for 40 cycles in a thermocycler (Biometra). Denaturation was performed at $94^{\circ} \mathrm{C}$ for $4 \mathrm{~min}$. Each cycle consisted of $94^{\circ} \mathrm{C}(30 \mathrm{~s}), 55^{\circ} \mathrm{C}(30 \mathrm{~s})$ and $72^{\circ} \mathrm{C}(30 \mathrm{~s})$. The last cycle was followed by a 7 -min extension period at $72^{\circ} \mathrm{C}$.

PCR products $(10 \mu \mathrm{l})$ from both virus groups and the controls were mixed with $2 \mu$ loading buffer (MBI Fermentas), electrophoresed on a $1.5 \%$ agarose gel, stained with ethidium bromide and visualized under UV light.

Experiment 2: blastocyst injection with viral-exposed $\mathrm{mESCs}$

\section{Culture of mESCs with MHV-A59 and MMVp}

The mESC line with a $129 / \mathrm{SvPas}$ genetic background was provided at passage 13 (P13) by W. Wurst, Helmholtz Center Munich, Neuherberg, Germany and showed GLT. Previous to their use in the present study, mESCs were cultured on mitomycin C-inactivated $(1 \mathrm{mg} / \mathrm{ml})$ murine embryonic feeder cells and passaged every 2 days. Both mESCs and feeder cells were free of mycoplasmas, pathogens listed in the FELASA recommendations and murine norovirus. Culture of the mESCs was performed in DMEM high glucose, supplemented with $15 \%$ fetal calf serum, $1 \%$ sodium pyruvate, $0.1 \mathrm{mM} \beta$-mercaptoethanol, $2 \mathrm{mM}$ glutamine, and 1,000 IU/ml LIF (Chemicon International Ltd, Hofheim, Germany).

A total of $1.134 \times 10^{6} \mathrm{mESCs}$ in the 13th passage (P13) was seeded at a density of $2 \times 10^{4}$ cells $/ \mathrm{cm}^{2}$ in $0.1 \%$ gelatin-coated $10-\mathrm{cm}$ Petri dishes without feeder cells and cultured for five passages $(\mathrm{P} 13+5)$. At each of the five passages, trypsinized cells were allowed to sediment for approximately 15-30 min in tubes and mESCs for further culture were taken from the top of the column thereby removing feeder cells, which settled to the bottom of the tubes. At $\mathrm{P} 13+5$, the mESCs were then exposed to $10^{4}$ or $10^{-1} \mathrm{TCID}_{50}$ MHV-A59 or $10^{-1} \mathrm{TCID}_{50} \mathrm{MMVp} /$ cell. After $6 \mathrm{~h}$ exposure to the virus, the inoculum was removed and replaced with ESC culture medium. Control mESCs were not exposed to the viruses. For continued culture over four $(\mathrm{P} 13+5+4$, MHVA59) or five passages $(\mathrm{P} 13+5+5$, MMVp $)$ in $0.1 \%$ gelatin-coated $10-\mathrm{cm}$ Petri dishes without feeder cells, mESCs inoculated with $10^{-1}$ TCID $_{50}$ virus/cell were passaged every 2 days. mESCs 
exposed to $10^{4} \mathrm{TCID}_{50} \mathrm{MHV}-\mathrm{A} 59 /$ cell for $6 \mathrm{~h}$ were used for blastocyst injection.

At each passage, cells were washed twice with PBS (Gibco, Invitrogen ${ }^{\mathrm{TM}}$, Auckland, New Zealand), once with trypsin/EDTA (Biochrom AG, Berlin, Germany) and then trypsinized. The number of mESCs found in the trypsinized cell suspensions was determined by the use of a hemocytometer (Hycor Biomedical Inc., Kassel, Germany). The trypsinized cell suspensions for further culture from each dish were pooled according to the experimental group. The cell-free supernatants were stored at $-80^{\circ} \mathrm{C}$ until titrated. The viability, the viral status, and the pluripotency status of the trypsinized mESCs from two replications was determined at $\mathrm{P} 13+5+1$ by flow cytometry as described below. For determination of growth, blastocyst injection and titration, further two replications each were performed on two different days (cultures 1 and 2).

\section{Antibodies and flow cytometry}

Anti-POU5F1 (formerly known as Oct-4) monoclonal antibodies (clone 9E3, Chemicon, Chandlers Ford, UK) were labeled with Cy5 monoreactive dye (Amersham, Freiburg, Germany) as recommended by the manufacturer. Anti-MHV-A59 and antiMMVp sera were collected from seropositive mice at our facility. The immunoglobulin G (IgG) fraction was purified using Prot-G Fast Flow chromatography (Amersham) and labeled with fluorescein isothiocyanate (FITC).

All cells were covalently stained with ethidium monoazide (EMA; Molecular Probes, Karlsruhe, Germany) in order to discriminate dead cells. They were fixed with $1 \%$ paraformaldehyde (PFA; Sigma, Deisenhofen, Germany), permeabilized using $0.2 \%$ saponin (Sigma) and labeled with the abovedescribed antibodies. The cells were processed with a LSRII flow cytometer (Becton Dickinson, Heidelberg, Germany) or a CyAn flow cytometer (DacoCytomation, Hamburg, Germany). The data were analyzed using the FloJo software (Tree Star, Ashland, USA).

\section{Virological examination of the cell culture supernatants}

The cell-free supernatants from the respective passages of the cultures with $10^{-1}$ TCID $_{50}$ MHV-A59 or
$10^{-1} \mathrm{TCID}_{50} \mathrm{MMVp} / \mathrm{cell}$ were titrated as described above for the viral stocks. The viral titers were calculated using the Spearman-Kaerber method (Spearman 1908; Kaerber 1931).

\section{Blastocyst injection with viral-exposed mESCs and embryo transfer}

After $6 \mathrm{~h}$ exposure to the viruses or after four (MHVA59) or five (MMVp) passages, 15-20 mESCs were injected into each blastocyst. Control blastocysts received non-viral-exposed mESCs. Blastocyst injections, embryo transfers to $\mathrm{d} 2.5$ pseudopregnant recipients and blood sampling were carried out with controls first. The serological status of recipients and pups was determined as described for Experiment 1 .

\section{Germline transmission}

To determine if the mESCs contributed to the germline, chimeras obtained were mated with C57BL/6 mice. The litter size, color, and gender of mice were recorded. Progeny were either agouti with a light-colored belly (GLT, originating from the 129 $\mathrm{Sv} / \mathrm{J}$ strain) or black in color (wild type, originating from the C57BL/6 strain).

\section{Statistical analysis}

Experimental groups were compared by Fisher's exact test. For the average number of cells found per replicate after culture of virus-exposed and control mESCs over passages, a Duncan's multiple range test was carried out. This test controlled the Type I comparison wise error rate and allowed a ranking of the cell numbers by passage number and treatment. The global level of significance was chosen to be 0.05 . All statistical analyzes were performed using SAS (SAS/STAT User's Guide, Version 9.1. Cary, NC; SAS Institute Inc., 2003).

\section{Results}

Experiment 1: injection of blastocysts with viral suspensions and embryo transfer

In a first step, blastocysts were microinjected with the viral stocks to determine whether the recipients 
Table 1 Results of blastocyst injection with MHV-A59 and MMVp suspensions and transfer into d2.5 pseudopregnant recipients

\begin{tabular}{|c|c|c|c|c|c|c|c|c|c|c|}
\hline \multirow[t]{3}{*}{ Virus } & \multirow{3}{*}{$\begin{array}{l}\text { Virus concentration } \\
\text { (TCID }_{50} / \text { blastocyst) }\end{array}$} & \multirow{3}{*}{$\begin{array}{l}\text { Number } \\
\text { of litters/ } \\
\text { Number of } \\
\text { recipients }\end{array}$} & \multirow{3}{*}{$\begin{array}{l}\text { Total number } \\
\text { of live pups }(\%)\end{array}$} & \multicolumn{7}{|c|}{ Seropositive mice post embryo transfer } \\
\hline & & & & \multicolumn{5}{|c|}{ Recipients } & \multicolumn{2}{|c|}{ Progeny } \\
\hline & & & & $\mathrm{d} 14$ & $\mathrm{~d} 21$ & $\mathrm{~d} 28$ & $\mathrm{~d} 42$ & d63 & $\mathrm{d} 42$ & d63 \\
\hline MHV-A59 & $10^{0}$ & $3 / 5$ & $14 \mathrm{a}^{\mathrm{a}}$ & $2 / 5 \mathrm{a}$ & $3 / 5 \mathrm{a}$ & $3 / 5 \mathrm{a}$ & $3 / 5 \mathrm{a}$ & $3 / 5 \mathrm{a}$ & $4 / 11 \mathrm{a}^{\mathrm{b}}$ & $1 / 11 a^{c}$ \\
\hline MMVp & $10^{-5}$ & $4 / 4$ & $14 \mathrm{a}^{\mathrm{a}}$ & $0 / 4 \mathrm{a}$ & $0 / 4 a$ & $0 / 4 \mathrm{a}$ & $0 / 4 \mathrm{a}$ & $0 / 4 \mathrm{a}$ & $0 / 11 b$ & $0 / 11 \mathrm{a}$ \\
\hline Control & M2 medium & $2 / 2$ & $9 \mathrm{a}^{\mathrm{a}}$ & $0 / 2 \mathrm{a}$ & $0 / 2 \mathrm{a}$ & $0 / 2 \mathrm{a}$ & $0 / 2 \mathrm{a}$ & $0 / 2 \mathrm{a}$ & $0 / 6 a b$ & $0 / 6 a$ \\
\hline
\end{tabular}

Different online alphabets within columns indicate significant differences $(P<0.05)$

${ }^{a}$ Organs from three pups out of each group were investigated for the presence of MHV and/or MMV using PCR

b Pups originated from one litter

${ }^{c}$ Mice were seronegative between d84 and d112

would seroconvert and if the reproductive efficiency would become affected. Following blastocyst injection with MHV-A59 and embryo transfer, three from five recipients littered 14 pups (Table 1). A total of two from five and three from five recipients seroconverted by $\mathrm{d} 14$ and $\mathrm{d} 21$, respectively. With respect to the pups, four from one litter were seropositive for MHV on d42. By d63, only one pup was seropositive and by d112 post embryo transfer it no longer had detectable MHV antibodies. In the MMVp group, all four recipients littered 14 pups. MMVp antibodies were found neither in recipients nor in the pups. When control blastocysts were injected with M2 medium, two out of two recipients littered nine pups. During the experimental period, both recipients and pups in the control group were seronegative for MHV-A59 and MMVp. At d42, there was a significantly higher number of pups seropositive for MHVA59 (4/11) than for MMVp (0/11); $P<0.05$. PCR analysis revealed that samples analyzed from all nine pups were negative for MHV and/or MMV.

Experiment 2: culture of mESCs with MHV-A59 and MMVp

\section{Pluripotency and viral status}

The pluripotency and viral status, as measured by FACS, were determined at $\mathrm{P} 13+5+1$ (data not shown). The percentage of control mESCs positive for POU5F1 alone, or positive for both POU5F1 and MHV-A59, or positive for both POU5F1 and MMVp was on average $80 \%, 3 \%$, and $3 \%$, respectively. For cultures exposed to MHV-A59, the percentage of cells positive for POU5F1 alone, or positive for both POU5F1 and MHV-A59, or positive for MHV alone was $55 \%, 32 \%$, and $3 \%$, respectively. For cultures exposed to MMVp, the percentage of cells positive for POU5F1 alone, or positive for both POU5F1 and MMVp, or positive for MMV alone was $65 \%, 6 \%$, and $0 \%$, respectively.

\section{mESCs allow efficient replication of MHV-A59 but not $M M V p$}

From the four replications, the average number of trypsinized cells in the control group was $3.1 \times 10^{6}$ at $\mathrm{P} 13+5+1$ and $3.2 \times 10^{6}$ at $\mathrm{P} 13+5+4$ (Fig. 1). Culture of mESCs with MMVp led to $1.4 \times 10^{6}$ cells at $\mathrm{P} 13+5+1$ and $2.1 \times 10^{6}$ at $\mathrm{P} 13+5+4$. With respect to the cultures with MHV-A59, $0.8 \times 10^{6}$ cells were found at $\mathrm{P} 13+5+1$, and the number decreased to $1.4 \times 10^{4}$ cells at $\mathrm{P} 13+5+4$. The average viability of the trypsinized control mESCs, MHV-A59- and MMVp-exposed mESCs at P13 + 5 + 1 was $86 \%$, $88 \%$, and $89 \%$, respectively. Significant differences were observed in the mean number of cells from MMV cultures compared to MHV cultures at passage $\mathrm{P} 13+5+3$ and in the mean cell numbers from the control and MHV cultures in passage P13 $+5+4$ $(P<0.05)$.

At the first two passages of culture 1 with MHVA59, the titer of the supernatant was higher than $10^{10} \mathrm{TCID}_{50} / \mathrm{ml}$ decreasing to $10^{7.8} \mathrm{TCID}_{50} / \mathrm{ml}$ at the fourth passage (Table 2). At the first passage of 
Fig. 1 The average number of cells found per replicate $(n=4)$ after culture of virus-exposed and control mESCs over four passages. mESCs were infected with 0.1 TCID $_{50}$ MHV-A59 or MMVp per cell; controls were virus-free. The mESCs were passaged every 2 days

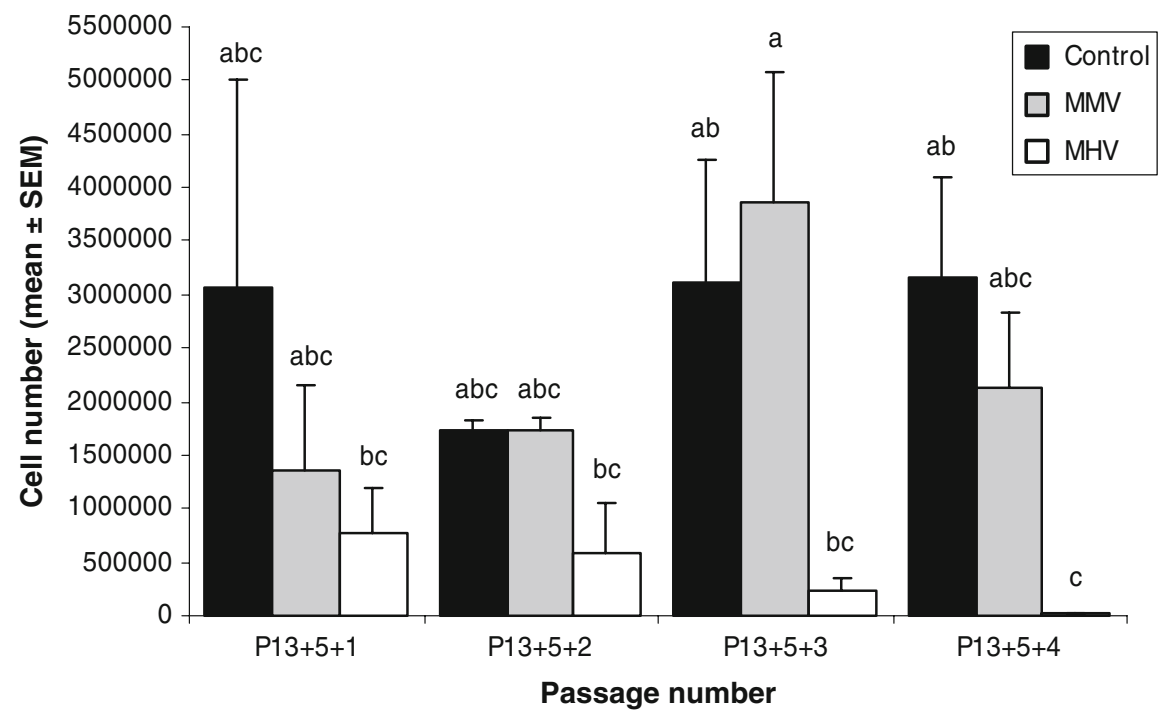

Table 2 Viral titer of supernatants after culture of mESCs with MHV-A59 or MMVp

\begin{tabular}{|c|c|c|c|c|}
\hline \multirow[t]{2}{*}{ Passage } & \multicolumn{2}{|c|}{$\begin{array}{l}\text { MHV-A59 } \\
\left(10^{-1} \mathrm{TCID}_{50} / \mathrm{ES} \text { cell }\right)\end{array}$} & \multicolumn{2}{|c|}{$\begin{array}{l}\text { MMVp } \\
\left(10^{-1} \mathrm{TCID}_{50} / \mathrm{ES} \text { cell }\right)\end{array}$} \\
\hline & Culture 1 & Culture 2 & Culture 1 & Culture 2 \\
\hline $\mathrm{P} 13+5+1$ & $>10^{10}$ & $>10^{10}$ & $10^{4.8}$ & $10^{3.8}$ \\
\hline $\mathrm{P} 13+5+2$ & $>10^{10}$ & $10^{8.3}$ & $10^{3.8}$ & $10^{3}$ \\
\hline $\mathrm{P} 13+5+3$ & $10^{8.3}$ & $10^{6.8}$ & 0 & $10^{2}$ \\
\hline $\mathrm{P} 13+5+4$ & $10^{7.8}$ & $10^{7.5}$ & 0 & $10^{1}$ \\
\hline $\mathrm{P} 13+5+5$ & n.d. & n.d. & 0 & $10^{1.3}$ \\
\hline
\end{tabular}

n.d., not done

culture 2, the titer of the supernatant was also higher than $10^{10} \mathrm{TCID}_{50} / \mathrm{ml}$ decreasing to $10^{7.5} \mathrm{TCID}_{50} / \mathrm{ml}$ at the fourth passage. With respect to MMVp, at the first passage of culture 1 , the viral titer of the supernatant was $10^{4.8} \mathrm{TCID}_{50} / \mathrm{ml}$ (Table 2). Viruses were not detected at the third to the fifth passage. At the first passage of culture 2, the viral titer of the supernatant was $10^{3.8} \mathrm{TCID}_{50} / \mathrm{ml}$ decreasing to $10^{1.3} \mathrm{TCID}_{50} / \mathrm{ml}$ at the fifth passage.

\section{Blastocyst injection with mESCs exposed} to $M H V-A 59$ and MMVp for $6 \mathrm{~h}$ resulted in the production of chimeras

When mESCs were exposed to $10^{4} \mathrm{TCID}_{50} \mathrm{MHV}$ A59/cell for $6 \mathrm{~h}$ and injected into blastocysts, one from five recipients littered two non-chimeric pups (Table 3). A total of four from five recipients seroconverted by day 14 and showed the presence of anti-MHV antibodies during the experimental period. Both pups were seropositive for MHV on d42 and, by d63, MHV antibodies were no longer found. When mESCs were exposed to $10^{-1}$ TCID $_{50}$ MHV-A59/cell for $6 \mathrm{~h}$ and injected into blastocysts, all five recipients littered 34 pups, 17 of which were chimeric. Neither recipients nor pups were seropositive for MHV-A59. In the MMVp group, when mESCs were cultured with $10^{-1}$ TCID $_{50}$ MMVp/cell for $6 \mathrm{~h}$ and injected into blastocysts, all five recipients littered 30 pups, three of which were chimeric. Neither recipients nor pups were seropositive for MMVp. Control mESCs resulted in all three recipients littering 16 pups, three of which were chimeric. Control mice showed no anti-MHV-A59 and antiMMVp antibodies.

A significantly higher number of chimeric pups was born in the MHV-A59 group than in the MMVp group where mESCs were inoculated with $10^{-1}$ TCID $_{50}$ MHV-A59 or MMVp/cell and in the control group $(P<0.05)$. Significant differences were observed in the number of seropositive recipients in the MHV-A59 group $\left(10^{4} \mathrm{TCID}_{50} /\right.$ cell $)$ compared to the MHV-A59 $\left(10^{-1}\right.$ TCID $_{50} /$ cell $)$ and the MMV groups $(P<0.05)$. With respect to the progeny, a significantly higher number of mice was seropositive in the MHV-A59 group $\left(10^{4}\right.$ TCID $_{50} /$ cell) on $\mathrm{d} 42(P<0.05)$. 
Table 3 Results of blastocyst injection with MHV-A59- and MMVp-exposed (P13 $+5+6 \mathrm{~h})$ mESCs and transfer into d2.5 pseudopregnant recipients

\begin{tabular}{|c|c|c|c|c|c|c|c|c|c|c|}
\hline \multirow[t]{3}{*}{ Virus } & \multirow{3}{*}{$\begin{array}{l}\text { Virus concentration } \\
\left(\mathrm{TCID}_{50} / \mathrm{ES} \text { cell }\right)\end{array}$} & \multirow{3}{*}{$\begin{array}{l}\text { Number of litters/ } \\
\text { Number of } \\
\text { recipients }\end{array}$} & \multirow{3}{*}{$\begin{array}{l}\text { Chimeric pups/ } \\
\text { number of } \\
\text { live pups }(\%)\end{array}$} & \multicolumn{7}{|c|}{ Seropositive mice days post embryo transfer } \\
\hline & & & & \multicolumn{5}{|c|}{ Recipients } & \multicolumn{2}{|c|}{ Progeny } \\
\hline & & & & $\mathrm{d} 14$ & $\mathrm{~d} 21$ & $\mathrm{~d} 28$ & $\mathrm{~d} 42$ & d63 & $\mathrm{d} 42$ & d63 \\
\hline MHV-A59 & $10^{4}$ & $1 / 5$ & $0 / 2(0) \mathrm{ab}$ & $4 / 5 \mathrm{a}$ & $4 / 5 \mathrm{a}$ & $4 / 5 \mathrm{a}$ & $4 / 5 \mathrm{a}$ & $4 / 5 \mathrm{a}$ & $2 / 2 \mathrm{a}$ & $0 / 2 \mathrm{a}$ \\
\hline MHV-A59 & $10^{-1}$ & $5 / 5$ & $17 / 34(50) b$ & $0 / 5 b$ & $0 / 5 b$ & $0 / 5 b$ & $0 / 5 b$ & $0 / 5 b$ & $0 / 34 b$ & $0 / 34 \mathrm{a}$ \\
\hline MMVp & $10^{-1}$ & $5 / 5$ & $3 / 30(10) \mathrm{a}$ & $0 / 5 b$ & $0 / 5 b$ & $0 / 5 b$ & $0 / 5 b$ & $0 / 5 b$ & $0 / 30 \mathrm{~b}$ & 0/30a \\
\hline Control & ESC medium & $3 / 3$ & $3 / 16(19) a$ & $0 / 3 a b$ & $0 / 3 a b$ & $0 / 3 a b$ & $0 / 3 a b$ & $0 / 3 a b$ & $0 / 16 b$ & $0 / 16 a$ \\
\hline
\end{tabular}

Different online alphabets within columns indicate significant differences $(P<0.05)$

Blastocyst injection with mESCs exposed to MHV-A59 and MMVp for 4 or 5 passages did not result in the production of chimeras

When mESCs were exposed to $10^{-1}$ TCID $_{50}$ MHVA59/cell for four passages and injected into blastocysts, five from 11 recipients littered 16 non-chimeric pups (Table 4). A total of nine from 11 and 10 from 11 recipients seroconverted by $\mathrm{d} 14$ and $\mathrm{d} 21$, respectively. All 16 pups were seropositive for MHV on d42. By d63, six pups were seropositive and by $d 84$ post embryo transfer no longer showed MHV antibodies. When mESCs were cultured with $10^{-1} \mathrm{TCID}_{50} \mathrm{MMVp} / \mathrm{cell}$ for five passages and injected into blastocysts, six from nine recipients littered 22 non-chimeric pups. Neither recipients nor pups were seropositive for MMVp throughout the experimental period. Blastocyst injection with control mESCs resulted in three from four recipients littering 19 pups, eight of which were chimeric. Control mice showed no antibodies for MHV-A59 and MMVp.
A significantly higher number of chimeric mice was obtained in the control group $(P<0.05)$. The number of seropositive recipients and pups was significantly higher in the MHV-A59 group $(P<0.05)$.

\section{Blastocyst injection with mESCs exposed to MHV-A59 and MMVp for 6 h but not after 4 or 5 passages resulted in the production of germline chimeras}

Table 5 presents a summary of the reproductive and serological data from the blastocyst injection with mESCs exposed to the virus either for $6 \mathrm{~h}$ or four (MHV-A59) or five (MMVp) passages. Following $6 \mathrm{~h}$ co-incubation of the mESCs with $10^{4}$ and $10^{-1}$ TCID $_{50}$ MHV-A59/cell, from a total of 50 embryos, 1 and 5 litters from five recipients consisted of $4 \%$ and $68 \%$ live pups, respectively, $(P<0.05)$. No germline chimeras were obtained from the group receiving mESCs which were co-incubated with

Table 4 Results of blastocyst injection with MHV-A59 $(\mathrm{P} 13+5+4)$ and MMVp $(\mathrm{P} 13+5+5)$ exposed mESCs and transfer into $\mathrm{d} 2.5$ pseudopregnant recipients

\begin{tabular}{|c|c|c|c|c|c|c|c|c|c|c|}
\hline \multirow[t]{3}{*}{ Virus } & \multirow{3}{*}{$\begin{array}{l}\text { Virus concentration } \\
\left(\mathrm{TCID}_{50} / \mathrm{ES} \text { cell }\right)\end{array}$} & \multirow{3}{*}{$\begin{array}{l}\text { Number } \\
\text { of litters/ } \\
\text { Number of } \\
\text { recipients }\end{array}$} & \multirow{3}{*}{$\begin{array}{l}\text { Chimeric pups/ } \\
\text { number of } \\
\text { live pups }\end{array}$} & \multicolumn{7}{|c|}{ Seropositive mice days post embryo transfer } \\
\hline & & & & \multicolumn{5}{|c|}{ Recipients } & \multicolumn{2}{|c|}{ Progeny } \\
\hline & & & & $\mathrm{d} 14$ & $\mathrm{~d} 21$ & $\mathrm{~d} 28$ & $\mathrm{~d} 42$ & d63 & $\mathrm{d} 42$ & d63 \\
\hline MHV-A59 & $10^{-1}$ & $5 / 11$ & $0 / 16 a$ & $9 / 11 \mathrm{a}$ & $10 / 11 \mathrm{a}$ & $10 / 11 \mathrm{a}$ & $10 / 11 \mathrm{a}$ & 10/11a & $16 / 16 \mathrm{a}$ & $6 / 16 \mathrm{a}^{\mathrm{a}}$ \\
\hline MMVp & $10^{-1}$ & $6 / 9$ & $0 / 22 \mathrm{a}$ & $0 / 9 b$ & $0 / 9 b$ & $0 / 9 b$ & $0 / 9 b$ & $0 / 9 b$ & $0 / 22 b$ & $0 / 22 b$ \\
\hline Control & ESC medium & $3 / 4$ & $8 \mathrm{~b} / 19 \mathrm{~b}$ & $0 / 4 b$ & $0 / 4 b$ & $0 / 4 b$ & $0 / 4 b$ & $0 / 4 b$ & $0 / 19 b$ & $0 / 19 b$ \\
\hline
\end{tabular}

Different online alphabets within columns indicate significant differences $(P<0.05)$

a All mice were seronegative by d84

b Three chimeras were females 
Table 5 Reproductive performance and serology of mice receiving blastocysts injected with MHV-A59 (P13 + 5 + 4) and MMVp $(\mathrm{P} 13+5+5)$ exposed mESCs

\begin{tabular}{|c|c|c|c|c|c|c|c|}
\hline \multirow[t]{3}{*}{ Parameter } & \multicolumn{7}{|c|}{ Period of culture and viral dose per mESC } \\
\hline & \multicolumn{4}{|c|}{$\mathrm{P} 13+5+6 \mathrm{~h}$} & \multicolumn{3}{|l|}{$\mathrm{P} 13+5+4 / 5$} \\
\hline & $\begin{array}{l}10^{4} \mathrm{TCID}_{50} \\
\mathrm{MHV}\end{array}$ & $\begin{array}{l}10^{-1} \text { TCID }_{50} \\
\text { MHV }\end{array}$ & $\begin{array}{l}10^{-1} \mathrm{TCID}_{50} \\
\mathrm{MMV}\end{array}$ & $\begin{array}{l}\text { Control ES } \\
\text { medium }\end{array}$ & $\begin{array}{l}10^{-1} \mathrm{TCID}_{50} \\
\mathrm{MHV}\end{array}$ & $\begin{array}{l}10^{-1} \mathrm{TCID}_{50} \\
\mathrm{MMV}\end{array}$ & $\begin{array}{l}\text { Control ES } \\
\text { medium }\end{array}$ \\
\hline $\begin{array}{r}\text { Progeny/embryos } \\
\text { transferred }(\%)\end{array}$ & $2 / 50(4) \mathrm{a}$ & $34 / 50(68) b$ & $30 / 50(60) b$ & $16 / 30(53) b$ & $16 / 110(15) c$ & $22 / 120(18) c$ & $19 / 40(48) b$ \\
\hline $\begin{array}{l}\text { Litters/number of } \\
\text { transfers performed }\end{array}$ & $1 / 5$ & $5 / 5$ & $5 / 5$ & $3 / 3$ & $5 / 11$ & $6 / 12$ & $3 / 4$ \\
\hline $\begin{array}{l}\text { Litters with chimeras } \\
\text { (number of mice) }\end{array}$ & $0 / 1(0)$ & $5 / 5(17) \mathrm{a}^{\mathrm{a}}$ & $2 / 5(3)$ & $2 / 3(3)$ & $0 / 5(0) b$ & $0 / 6(0)$ & $3 / 4(8)^{b}$ \\
\hline $\begin{array}{l}\text { Seropositive litters } \\
\quad \text { (number of mice) }\end{array}$ & $1 / 5(2)$ & $0 / 5(0) \mathrm{a}$ & $0 / 5(0)$ & $0 / 3(0)$ & $5 / 5(16) b$ & $0 / 6(0)$ & $0 / 4(0)$ \\
\hline $\begin{array}{l}\text { Seropositive litters with } \\
\text { chimeras (number } \\
\text { of mice) }\end{array}$ & $0 / 1(0)$ & $0 / 5(0)$ & $0 / 5(0)$ & $0 / 3(0)$ & $0 / 5(0)$ & $0 / 6(0)$ & $0 / 4(0)$ \\
\hline $\begin{array}{l}\text { Litters with germline } \\
\text { chimeras (number } \\
\text { of mice) }\end{array}$ & $0 / 1(0)$ & $3 / 5(8)$ & $2 / 5(3)$ & $2 / 2(3)$ & $0 / 5(0)$ & $0 / 6(0)$ & $3 / 3(8)$ \\
\hline $\begin{array}{l}\text { Germline chimeras/ } \\
\text { chimeras }\end{array}$ & $0 / 0(0)$ & $8 / 17$ & $3 / 3$ & $3 / 3$ & $0 / 0(0)$ & $0 / 0(0)$ & $5 / 8^{\mathrm{c}}$ \\
\hline Germline progeny & 0 & 56 & 20 & 20 & 0 & 0 & 31 \\
\hline $\begin{array}{l}\text { Progeny/germline } \\
\text { chimera }\end{array}$ & 0 & 7 & 6.7 & 6.7 & 0 & 0 & 6.2 \\
\hline
\end{tabular}

Different online alphabets within rows indicate significant differences $(P<0.05)$

a One non-germline female chimera was obtained

b Three female chimeras were obtained

c Two female germline chimeras were obtained

$10^{4} \mathrm{TCID}_{50}$ MHV-A59/cell. In addition, one out of five recipients from only this group was seropositive. With respect to $6 \mathrm{~h}$ co-incubation of the mESCs with $10^{-1}$ TCID $_{50}$ MHV-A59/cell, 17 chimeras were born to all five recipients that littered and eight chimeras from three litters showed GLT. On average, seven pups per germline chimera were born. One chimera was female which did not give birth to pups. None of the mice from this group had anti-MHV antibodies. In the $10^{-1} \mathrm{TCID}_{50} \mathrm{MMVp} /$ cell group, $60 \%$ of the embryos resulted in live pups. From all recipients that littered, three chimeras from two litters were obtained, all of which showed GLT. An average of 6.7 pups per germline chimera was born. Mice in this group were seronegative for MMV. In the control group, 53\% of the embryos resulted in live pups. From the three recipients that littered, three chimeras from two litters were obtained, all of which showed GLT. An average of 6.7 pups per germline chimera was born. Control mice were seronegative for MHV and MMV.

Following culture of the mESCs with $10^{-1}$ TCID $_{50}$ MHV-A59 or MMVp/cell for four or five passages, from a total of 110 and 120 embryos, respectively, five out of 11 and six out of 12 recipients gave birth to litters with 16 and 22 pups, respectively, $(P>0.05)$. No chimeras were obtained from these two groups. All five recipients from the MHV-A59 group that littered were seropositive while no anti-MMV antibodies were present in the recipients from the MMV group. From the control embryos, $48 \%$ resulted in live pups, the result being significantly different from that from both virus groups $(P<0.05)$. From the three recipients that littered, eight chimeras were obtained, five of which showed GLT. An average of 6.2 pups per germline chimera was born. Mice were seronegative for both MHV and MMV. Comparison of the MHV-A59 
group $\left(10^{-1}\right.$ TCID $_{50}$ MHV-A59/cell) after $6 \mathrm{~h}$ or after four passages showed that there were significant differences in the number of litters with chimeras $(5 / 5$ vs. 0/5, respectively) and in the number of seropositive litters $(0 / 5$ vs. $5 / 5$, respectively) $(P<0.05)$.

\section{Discussion}

The susceptibility of mESCs to infection with MHVA59 and MMVp and the risk of transmission of these two viruses to mice by mESCs during blastocyst injection and embryo transfer were investigated in the present study. In addition, the effect of these viruses on the GLT of the mESCs was determined. MHV and MMV were chosen since they are among the most prevalent viruses found in contemporary mouse colonies and MHV replicates in the cytoplasm while MMV replicates in the nucleus of the cell.

In a first step, blastocysts were microinjected with approximately $1 \mathrm{nl}$ of the viral stocks to determine whether the recipients would seroconvert and if the reproductive efficiency would become affected. The present data show that microinjection of blastocysts with titers as high as $10^{9}$ TCID $_{50}$ MHV-A59/ml leads to seroconversion of the recipients and, in some cases, the pups also have anti-MHV antibodies, which are of maternal origin. The titer of MMVp used in this study did not lead to seroconversion of the recipients and pups did not have anti-MMV antibodies, implicating that the viral titer was too low. Due to the small volume of liquid that was injected indeed one blastocyst would have received a maximum of $1 \mathrm{TCID}_{50}$ MHV-A59 or $10^{-5} \mathrm{TCID}_{50}$ MMVp and recipients would have received a maximum dose of 10 TCID $_{50}$ MHV-A59 or $10^{-4}$ TCID $_{50}$ MMVp since 10 blastocysts were transferred to each recipient. In addition, the reproductive efficiency did not appear to be affected by the presence of the viruses, even with the high MHV dose, most likely due to short-term exposure of the blastocysts to the viruses and a lack of viral replication in the embryos or fetuses themselves. All pups examined, including those born to seropositive recipients, were free of the virus, as shown by PCR analysis.

To our knowledge, there is only one report on the microinjection of a murine virus into zygotes followed by embryo transfer (Tebourbi et al. 2002). After microinjection of the murine cytomegalovirus
(MCMV) into the cytoplasm of zygotes with a titer of $10^{8}$ plaque-forming units (PFU)/ml, 10 washes with M2 medium and embryo transfer, these workers reported that the number of pups born per litter was not affected by the presence of MCMV. Even though PCR analysis detected MCMV DNA in in vitro cultured embryos none was found in the pups and the recipients (Tebourbi et al. 2002). In contrast, Baskar et al. (1993) injected 5-20 molecules MCMV DNA into the male pronucleus of each zygote with the same technique that is used for transgenesis and transferred the resulting blastocysts to recipients. These workers reported smaller litter sizes, fetal growth retardation, embryo resorption, abnormalities, and MCMV DNA in fetal mice. In the present study, pups from a MHV-seropositive mother showed the presence of anti-MHV antibodies which decreased by d112 post embryo transfer. Unfortunately, the amount of MCMV microinjected (Tebourbi et al. 2002) and the serological status of pups and recipients were not reported. With respect to the reproductive performance, the present results support the findings with those using MCMV (Tebourbi et al. 2002).

In the present study, inoculation of the mESCs with $0.1 \mathrm{TCID}_{50} /$ cell, culture, for $4-5$ passages and titration of the cell-free supernatants showed that a productive infection was observed in the culture with MHV-A59, whereas a restrictive infection was observed in the culture with MMVp. This is supported by the finding that titers of the supernatants from the cultures with MHV-A59 were over $10^{7}$ $\mathrm{TCID}_{50} / \mathrm{ml}$, whereas titers of the supernatants from the cultures with MMVp decreased with time or there was no detectable infectious virus present at later passages. A total of eight mESC lines of different genetic origin including B6, B6CBAF1 and 129/Sv, which were inoculated with 0.1 multiplicity of infection (moi), replicated MHV-2 and MHV-A59 over 2-3 days (Kyuwa 1997). The latter worker observed titers of over $10^{6} \mathrm{PFU} / \mathrm{ml}$ and little cytopathic effect. In contrast to the study by Kyuwa (1997), our results show that mESCs cultured with MHV-A59 led to a well-pronounced cytolysis, leading to a decrease in cell numbers. In the study by Kyuwa (1997), no information is available on the number of cells cultured and/or infected by the two MHV strains and culture was only short-term, in contrast to the present study. A more-intensive in vitro study, however, was performed by Okumura 
et al. (1996) who demonstrated that $129 / \mathrm{SvJ}$-derived mESCs, which were inoculated with the less pathogenic MHV-2 at a moi of 1 , replicated the virus for over 60 days, all cells were infected, viral titers reached $10^{6}-10^{9} \mathrm{PFU} / \mathrm{ml}$ and the pluripotency of the mESCs was not affected.

Unlike the culture with MHV, in the present study, no noticeable changes were observed with MMVp, and cell numbers increased during culture. During routine mESC culture, viral strains causing cytolysis such as MHV-A59 would be detected morphologically while those that do not cause overt effects such as MHV-2 (Okumura et al. 1996) could remain undetected unless appropriate diagnostic methods are employed.

Rodent parvoviruses bind to surface receptors which are expressed on most cells and do not appear to integrate into host chromosomes during either lytic or persistent infections (Cornelis et al. 2004). Parvovirus replication in permissive cells within 20-30 h (Ward and Tattersall 1982) leads to the release of progeny virions and is usually associated with cell death. In a restrictive host culture, the viral yield from culture is always less than the multiplicity required to obtain it. Even at a very high dose of 5-10 PFU/cell, only $0.1-5 \%$ of cells are productively infected and die (Ward and Tattersall 1982). The survivors (95-99\%) continue to grow and are not infectable at the original multiplicity and therefore infections dilute out rapidly. A previous study showed restrictive infection of murine embryonal carcinoma cells (mECCs) with MMV (Miller et al. 1977). Less than $0.1 \%$ positive nuclei were detected when cells were infected with $10 \mathrm{PFU} / \mathrm{cell}$ (Miller et al. 1977). Blocking of replication of MMV in teratocarcinoma stem cells is not total; a small fraction of infected cells produce capsid antigen (Miller et al. 1977). In the present study, $6 \%$ of the cells were found to be positive for both POU5F1 and MMV at P13 $+5+1$ by FACS analysis, thus supporting previous results (Miller et al. 1977; Ward and Tattersall 1982). With respect to replication of MMV, the mESCs used in the present investigation are similar to mECCs. Resistance to infection by MMV may involve the transport of viral antigen or capsid to the nucleus (Tattersall 1978) or as a result of post-adsorptional events rather than of the lack of binding of virus to the surface of the target cell (Spalholz and Tattersall 1983; Tattersall and Bratton 1983).
The present results show that blastocyst injection with mESCs exposed to $10^{-1}$ TCID $_{50}$ MHV-A59 and MMVp for $6 \mathrm{~h}$ resulted in the production of germline chimeras. Furthermore, recipients were seropositive for MHV-A59 but not for MMVp only when a high dose of $10^{4} \mathrm{TCID}_{50} / \mathrm{mESC}$ was used. Pups were seropositive for MHV-A59 when their mothers were seropositive by day 14 post embryo transfer. Furthermore, this antibody was maternal in origin since it decreased with time after birth. With respect to germline chimera obtained, a similar number of progeny was born when mESCs were virus-free or cultured with $10^{-1}$ TCID $_{50}$ MHV-A59 or MMVp/cell for $6 \mathrm{~h}$. Culture with the higher dose $\left(10^{4} \mathrm{TCID}_{50} /\right.$ mESC) of MHV-A59 did not lead to the production of chimeras. Similarly, culture with $10^{-1}$ TCID $_{50}$ MHVA59 or MMVp/cell over four or five passages did not lead to the production of chimeras whereas the controls were not affected. Furthermore, similar to the results for the $6 \mathrm{~h}$ short-term culture with $10^{4} \mathrm{TCID}_{50} \mathrm{MHV}$ A59/mESC, seroconversion also occurred with longterm MHV-exposed $(\mathrm{P} 13+5+4)$ but not MMVexposed $(\mathrm{P} 13+5+5)$ mESCs. Blastocyst injection with mESCs which were previously incubated for $1 \mathrm{~h}$ with $1 \mathrm{PFU} \mathrm{MCMV} /$ cell led to the development of normal offspring that contained no MCMV DNA (Tebourbi et al. 2002). However, no data is available on the antibody status of the recipients and pups from that study. Similar to the present study where mESCs were incubated with the viruses for $6 \mathrm{~h}$, the lack of an effect on the reproductive performance by co-incubation of mESCs with MCMV may be due to short-term exposure.

The number of passages of mESCs could influence the GLT. Nagy et al. (1993) reported that prolonged in vitro culture affected the initial totipotency of the $\mathrm{R} 1$ cell line $(129 / \mathrm{Sv} \times 129 / \mathrm{Sv}-\mathrm{CP}$ background $)$, whereas sublines were capable of further culture, retaining their totipotency and giving rise to viable chimeras. In the present study, mESCs were cultured without feeder cells on gelatin to ensure reliable data production from the mESCs alone. Due to the low numbers of mESCs from cultures inoculated with MHV-A59 at later passages it was not possible to measure the pluripotency status using FACS. Instead, the mESCs were used for blastocyst injections. However, at $\mathrm{P} 13+5+1$, the percentage of mESCs positive for POU5F1 alone was highest in the control group (80\%) compared to the MHV (55\%) and MMV 
groups (65\%). The true test of pluripotency of mESCs is the contribution to the germline. In this study, the production of germline chimeras was affected, indicating that the lack of GLT was due to the presence of the viruses and not to the number of passages since virus-free control mESCs led to germline chimeras. The reason for a lack of GLT in MHV-exposed mESCs may be attributed to effects associated with cytolysis, perhaps due to inhibition of the host macromolecular synthesis, but the mechanism remains unclear as to why the GLT of MMVexposed mESCs was affected despite a restrictive infection and a lack of anti-MMV antibodies in the recipients and pups. The latter observation may be due to changes in the nucleus of the mESCs since MMV replicates in the nucleus of permissive cells but this phenomenon warrants further study.

In conclusion, this study showed that viruses such as MHV and MMV in mESC cultures influence the GLT of the mESCs. In view of the increasing use of mESCs in biomedical research, it is of paramount importance to screen mESCs for unwanted microorganisms prior to their use. In this way, early detection could save valuable resources while misinterpretations of experimental results could be avoided. In addition, use of pathogen-free mESCs is of importance to animal welfare since the number of mice used for genetic engineering can be reduced.

Acknowledgments We thank the animal caretakers and S. Weidemann for technical assistance.

\section{References}

Barthold SW (1986) Mouse hepatitis virus biology and epizootiology. In: Bhatt PN, Jacoby RO, Morse HCIII, New AE (eds) Viral and mycoplasmal infections of laboratory rodents: effects on biomedical research. Academic, New York, pp 571-601

Baskar JF, Furnari B, Huang ES (1993) Demonstration of developmental anomalies in mouse fetuses by transfer of murine cytomegalovirus DNA-injected eggs to surrogate mothers. J Infect Dis 167:1288-1295

Bootz F, Sieber I, Popovic D, Tischhauser M, Homberger FR (2003) Comparison of the sensitivity of in vivo antibody production tests with in vitro PCR-based methods to detect infectious contamination of biological materials. Lab Anim 37:341-351

Brayton PR, Ganges RG, Stohlman SA (1981) Host cell nuclear function and murine hepatitis virus replication. J Gen Virol 56:457-460. doi:10.1099/0022-1317-56-2-457
Cornelis JJ, Salome N, Dinsart C, Rommelaere J (2004) Vectors based on autonomous parvoviruses: novel tools to treat cancer? J Gene Med 6(suppl 1):S193-S202. doi:10.1002/jgm.502

Dempsey WL, Smith AL, Morahan PS (1986) Effect of inapparent murine hepatitis virus infections on macrophages and host resistance. J Leukoc Biol 39:559-565

Fox JG, Murphy JC, Igras VE (1977) Adverse effects of mouse hepatitis virus on ascites myeloma passage in the BALB/ eJ mouse. Lab Anim Sci 27:173-179

Gosert R, Kanjanahaluethai A, Egger D, Bienz K, Baker SC (2002) RNA replication of mouse hepatitis virus takes place at double-membrane vesicles. J Virol 76:36973708. doi:10.1128/JVI.76.8.3697-3708.2002

Gossler A, Doetschman T, Korn R, Serfling E, Kemler R (1986) Transgenesis by means of blastocyst-derived embryonic stem cell lines. Proc Natl Acad Sci USA 83:9065-9069. doi:10.1073/pnas.83.23.9065

Kaerber G (1931) Beitrag zur kollektiven Behandlung pharmakologischer Reihenversuche. Arch Exp Pathol Pharmakol 162:480-483. doi:10.1007/BF01863914

Kraft V, Blanchet HM et al (1994) Recommendations for the health monitoring of mouse, rat, hamster, guinea pig and rabbit breeding colonies. Report of the Federation of European Laboratory Animal Science Associations (FELASA) working group on animal health accepted by the FELASA board of management, November 1992. Lab Anim 28:1-12. doi:10.1258/002367794781065933

Kyriazis AP, DiPersio L, Michael JG, Pesce AJ (1979) Influence of the mouse hepatitis virus (MHV) infection on the growth of human tumors in the athymic mouse. Int $\mathrm{J}$ Cancer 23:402-409. doi:10.1002/ijc.2910230320

Kyuwa S (1997) Replication of murine coronaviruses in mouse embryonic stem cell lines in vitro. Exp Anim 46:311-313. doi:10.1538/expanim.46.311

Kyuwa S, Xiao Y, Toyoda Y, Sato E (1997) Characterization of embryonic stem-like cell lines derived from embryoid bodies. Exp Anim 46:11-16. doi:10.1538/expanim.46.11

Linser P, Bruning H, Armentrout RW (1979) Uptake of minute virus of mice into cultured rodent cells. J Virol 31:537-545

Lussier G (1988) Potential detrimental effects of rodent viral infections on long-term experiments. Vet Res Commun 12:199-217. doi:10.1007/BF00362802

Mahabir E, Bulian D, Needham J, Mayer A, Mateusen B, Soom AV et al (2007) Transmission of mouse minute virus (MMV) but not mouse hepatitis virus (MHV) following embryo transfer with experimentally exposed in vivo-derived embryos. Biol Reprod 76:189-197. doi:10.1095/biolreprod.106.056135

Miller RA, Ward DC, Ruddle FH (1977) Embryonal carcinoma cells (and their somatic cell hybrids) are resistant to infection by the murine parvovirus MVM, which does infect other teratocarcinoma-derived cell lines. J Cell Physiol 91:393-401. doi:10.1002/jcp.1040910309

Nagy A, Rossant J, Nagy R, Abramow-Newerly W, Roder JC (1993) Derivation of completely cell culture-derived mice from early-passage embryonic stem cells. Proc Natl Acad Sci USA 90:8424-8428. doi:10.1073/pnas.90.18.8424

Nagy A, Gertsenstein M, Vintersten K, Behringer R (2003) Manipulating the mouse embryo. Cold Spring Harbor Laboratory, New York 
Nicklas W, Baneux P, Boot R, Decelle T, Deeny AA, Fumanelli $M$ et al (2002) Recommendations for the health monitoring of rodent and rabbit colonies in breeding and experimental units. Lab Anim 36:20-42. doi:10.1258/ 0023677021911740

Nicklas W, Weiss J (2000) Survey of embryonic stem cells for murine infective agents. Comp Med 50:410-411

Okumura A, Machii K, Azuma S, Toyoda Y, Kyuwa S (1996) Maintenance of pluripotency in mouse embryonic stem cells persistently infected with murine coronavirus. J Virol 70:4146-4149

Quinn P, Barros C, Whittingham DG (1982) Preservation of hamster oocytes to assay the fertilizing capacity of human spermatozoa. J Reprod Fertil 66:161-168. doi:10.1530/ jrf.0.0660161

Spalholz BA, Tattersall P (1983) Interaction of minute virus of mice with differentiated cells: strain-dependent target cell specificity is mediated by intracellular factors. J Virol 46:937-943

Spearman C (1908) The method of 'right and wrong cases' (constant stimuli) without Gauss's formulae. Br J Psychol 2:227-242
Tattersall P (1972) Replication of the parvovirus MVM. I. Dependence of virus multiplication and plaque formation on cell growth. J Virol 10:586-590

Tattersall P (1978) Susceptibility to minute virus of mice as a function of host-cell differentiation. In: Ward D, Tattersall $\mathrm{P}$ (eds) Replication of mammalian parvoviruses. Cold Spring Harbor Laboratory, New York, pp 131-149

Tattersall P, Bratton J (1983) Reciprocal productive and restrictive virus-cell interactions of immunosuppressive and prototype strains of minute virus of mice. $\mathrm{J}$ Virol 46:944-955

Taylor K, Copley CG (1994) Detection of rodent RNA viruses by polymerase chain reaction. Lab Anim 28:31-34

Tebourbi L, Testart J, Cerutti I, Moussu JP, Loeuillet A, Courtot AM (2002) Failure to infect embryos after virus injection in mouse zygotes. Hum Reprod 17:760-764. doi:10.1093/humrep/17.3.760

Ward DC, Tattersall PJ (1982) Minute virus of mice. In: The mouse in biomedical research. Academic Press, Inc., New York, pp 313-333 